\title{
Thrombolysis for acute stroke with special emphasis on the very old: experience from a single Dutch centre
}

\section{R J van Oostenbrugge, R M M Hupperts, J Lodder}

The aim of this study was to describe the clinical experience in 184 consecutive stroke patients first-ever treated with recombinant tissue plasminogen activator (rt-PA) at a single Dutch centre, with special emphasis on results among the very old. Outcome parameters were the modified Rankin scale (mRs) at 3 months and symptomatic intracranial haemorrhage (SICH). Outcome was related to age. A total of 184 patients were treated of whom 45 were 80 years of age or older $(24 \%)$. Sixty two $(45 \%)$ of 139 patients $<80$ years of age and $12(27 \%)$ of 45 patients $\geqslant 80$ years of age had a favourable outcome defined as an $m$ Rs score of 0 or 1 (OR $2.21 ; 95 \% \mathrm{Cl}: 1.06$ to 4.46 ). There was a good outcome (mRs score $\leqslant 2$ ) in $88(63 \%)$ and $16(36 \%)$ patients, respectively (OR $3.13 ; 95 \% \mathrm{Cl}: 1.55$ to 6.30 ). $\mathrm{SICH}$ was observed in four of $139(2.9 \%)$ patients $<80$ years of age and in five of $45(11.1 \%)$ patients $\geqslant 80$ years of age (OR 4.22; $95 \% \mathrm{Cl}: 1.08$ to 16.46 ). The results of this study underline the uncertainty regarding the risk/benefit ratio of rt-PA treatment in acute stroke in patients over 80 years of age.

$\mathrm{T}$ he use of intravenous recombinant tissue plasminogen activator (rt-PA) in acute stroke has been shown to improve outcome, and is currently the only evidence based specific treatment for acute ischaemic stroke. ${ }^{12}$ Although the evidence is based on a rather small number of patients, thrombolysis has become routine clinical practice in many centres, but uncertainties remain. ${ }^{34}$ It is unclear, for example, what the risk/benefit ratio is in patients over 80 years of age.

A number of studies compared patient characteristics and treatment results in observational series with those of the NINDS trial..$^{5-10}$ Although thrombolysis may be successful in very old patients, none of these studies provided useful estimates of the risk/benefit ratio in this group. Up to now, only two case series describing the results of thrombolysis for acute stroke in the very old have been published. ${ }^{11}{ }^{12}$ However, one study used strict selection criteria whereas the other did not compare outcome between the very old and remaining patients. We report on 184 consecutive first-ever rt-PA treated patients at the University Hospital Maastricht, The Netherlands, 45 of whom were 80 years of age or older.

\section{METHODS}

The University Hospital is the only hospital in the Maastricht region and serves approximately 200000 people. We began using rt-PA in acute stroke in July 1998, and from then on all treated patients were entered into a database. We included in this study only patients treated for the first time with rt-PA. The inclusion and exclusion criteria for thrombolytic therapy were based on the NINDS study protocol, with the following additional criteria from the ECASS trials: early infarct signs in more than one third of the middle cerebral artery (MCA) territory on CT or severely impaired consciousness, or both. ${ }^{13}$ There was no upper age limit for eligibility. Stroke severity on admission was assessed using the National Institutes of Health Stroke Scale (NIHSS). ${ }^{14}$ Demographic data, stroke risk factors, and systolic and diastolic blood pressure measurements were collected and the time to treatment from stroke onset was noted. Symptomatic intracerebral haemorrhages, defined according the criteria used in the NINDS trial and classified symptomatic if not seen on a previous CT scan and there had subsequently been either suspicion of a haemorrhage or any decline in neurological status, were recorded. Patients had a routine follow up CT scan $24 \mathrm{~h}$ after thrombolytic therapy. Final outcome was assessed after 3 months using the modified Rankin scale (mRs). Favourable outcome was defined as mRs grade 0 or 1 , whereas good outcome, that is, being functionally independent, was defined as mRs score $\leqslant 2$. Data on outcome and bleeding complications were compared with figures from the NINDS trial, as well as with some descriptive studies. In addition, we compared baseline characteristics between patients below and those over 80 years of age using descriptive statistics as well as univariate analysis $\left(\chi^{2}\right.$ or Fisher's exact test). Differences in outcome and occurrence of symptomatic intracranial haemorrhage $(\mathrm{SICH})$ between the two groups were analysed using odds ratios with 95\% confidence intervals.

\section{RESULTS}

Over 6.5 years (July 1998-December 2004) rt-PA was administered 193 times to 184 patients, of whom 109 were men $(59 \%)$ and 75 were women $(41 \%)$, with a mean age of 70 years (median 74 years, range 24-97). Only the results of the first-ever treatment with rt-PA were analysed in these 184 patients. Forty five patients $(24 \%)$ were over 80 years of age (mean 85 years, median 84, and range 80-97) and 139 patients were below 80 years of age (mean 66 years, median 68 , and range $24-79)$. One hundred and forty patients (76\%) had a cortical syndrome and 37 had a lacunar syndrome $(20 \%)$. Seven patients $(4 \%)$ had basilar artery territory ischaemia. The median NIHSS score for all patients was 12 (range 2-25). Mean \pm standard deviation (SD) time from onset to treatment for all patients was $142 \pm 35 \mathrm{~min}$. In 10 patients $(5.4 \%)$ early ischaemic changes in more than one third of the MCA territory were seen on CT. Baseline characteristics of patients aged $<80$ years of age and those $\geqslant 80$ years of age are shown in table 1 .

There were fewer males (40\% $v$ 65\%; $\mathrm{p}=0.003)$ and smokers $(7 \% \vee 30 \% ; \mathrm{p}=0.001)$ and a significant higher incidence of congestive and ischaemic heart disease in

Abbreviations: MCA, middle cerebral artery; mRs, modified Rankin scale; NIHSS, National Institutes of Health Stroke Scale; RCT, randomised controlled trial; rt-PA, recombinant tissue plasminogen activator; $\mathrm{SICH}$, symptomatic intracranial haemorrhage 
Table 1 Comparison of baseline characteristics of patients under and over 80 years of age treated with rtPA

\begin{tabular}{|c|c|c|c|}
\hline & $\begin{array}{l}\text { Age }<80 \\
\text { years } \\
(n=139)\end{array}$ & $\begin{array}{l}\text { Age } \geqslant 80 \\
\text { years } \\
(n=45)\end{array}$ & $\begin{array}{l}\mathrm{p} \\
\text { value }\end{array}$ \\
\hline $\begin{array}{l}\text { Mean age (median; } \\
\text { range), years }\end{array}$ & $\begin{array}{l}66(68 ; \\
24-79)\end{array}$ & $\begin{array}{l}85(84 ; \\
80-97)\end{array}$ & - \\
\hline Male & $91(65 \%)$ & $18(40 \%)$ & 0.003 \\
\hline Hypertension & $67(48 \%)$ & $26(58 \%)$ & 0.31 \\
\hline Diabetes mellitus & $28(20 \%)$ & $8(18 \%)$ & 0.83 \\
\hline Current smoker & $42(30 \%)$ & $3(7 \%)$ & 0.001 \\
\hline Prior stroke & $22(16 \%)$ & $7(16 \%)$ & 1.00 \\
\hline Atrial fibrillation & $19(14 \%)$ & $9(20 \%)$ & 0.34 \\
\hline Congestive heart disease & $5(4 \%)$ & $6(13 \%)$ & 0.03 \\
\hline Ischaemic heart disease & $35(25 \%)$ & $20(44 \%)$ & 0.02 \\
\hline \multicolumn{4}{|l|}{$\begin{array}{l}\text { Pre-treatment blood } \\
\text { pressure (mean } \pm \text { SD) }\end{array}$} \\
\hline Systolic, mm $\overline{\mathrm{Hg}}$ & $156 \pm 22$ & $163 \pm 25$ & 0.10 \\
\hline Diastolic, $\mathrm{mm} \mathrm{Hg}$ & $83 \pm 12$ & $82 \pm 10$ & 0.57 \\
\hline \multicolumn{4}{|l|}{ Pre-treatment NIHSS score } \\
\hline$\leqslant 10$ & $56(40 \%)$ & $16(36 \%)$ & 0.60 \\
\hline $11-15$ & $42(30 \%)$ & $15(33 \%)$ & 0.71 \\
\hline$\geqslant 16$ & $41(30 \%)$ & $14(31 \%)$ & 0.85 \\
\hline $\begin{array}{l}\text { Early ischaemic changes } \\
\text { on CT in more then } 1 / 3 \\
\text { of the MCA territory }\end{array}$ & $9(7 \%)$ & $1(2 \%)$ & 0.46 \\
\hline $\begin{array}{l}\text { Time to treatment } \\
(\text { mean } \pm S D), \min \end{array}$ & $140 \pm 34$ & $148 \pm 36$ & 0.17 \\
\hline
\end{tabular}

patients over 80 years of age. Other baseline characteristics, especially those related to outcome after rt-PA, that is, NIHSS score, time to treatment, systolic and diastolic blood pressure, and early ischaemic changes on CT, were not significantly different.

Outcome at 3 months (mRs score) for all patients and the two groups defined by age is shown in table 2 .

Seventy four patients $(40 \%)$ had a favourable outcome (mRs score 0 or 1 ) and 104 patients $(57 \%)$ had a good outcome (mRs score $\leqslant 2$ ). Sixty two $(45 \%)$ of 139 patients $<80$ years of age and $12(27 \%)$ of 45 patients $\geqslant 80$ years of age had a favourable outcome. The corresponding figures for good outcome were $88(63 \%)$ and 16 (36\%), respectively. These differences in outcome were statistically significant for both definitions (favourable outcome: OR 2.21; 95\% CI: 1.06 to 4.46 , and good outcome: OR 3.13 ; $95 \%$ CI: 1.55 to 6.30 ).

SICH occurred in nine patients $(4.9 \%)$, of whom eight died. NIHSS scores were higher in patients with SICH (median $14 \mathrm{v}$ 12) and time to treatment was slightly longer (151 v $141 \mathrm{~min})$. These differences were not statistically significant. SICH was observed in four of the $139(2.9 \%)$ patients $<80$ years of age, and in five of the 45 (11.1\%) patients $\geqslant 80$ years of age (OR $4.22 ; 95 \%$ CI: 1.08 to 16.46). Patients $\geqslant 80$ years of age with SICH were treated later (mean $156 \pm 23 \vee 145 \pm 28 \mathrm{~min})$ and had slightly higher NIHSS scores (mean $14 \pm 5 \vee 13 \pm 6$ ). These differences were not statistically significant. In three of the five patients $\geqslant 80$ years

Table 2 Outcome at 3 months assessed by modified Rankin score in all 184 patients and according to age ( $<80$ and $\geqslant 80$ years)

\begin{tabular}{lllll}
\hline & $\mathbf{0 - 1}$ & $\mathbf{2 - 3}$ & $\mathbf{4 - 5}$ & Death \\
\hline All $(n=184), \%$ & 40 & 25 & 13 & 22 \\
Age $<80(n=139), \%$ & 45 & 27 & 13 & 16 \\
Age $\geqslant 80(n=45), \%$ & 27 & 20 & 13 & 40 \\
\hline
\end{tabular}

of age, SICH occurred in areas not affected by infarction, whereas in patients $<80$ years of age it only occurred in infarcted tissue.

\section{DISCUSSION}

Although there has been some debate whether results similar to those found in the NINDS thrombolysis trial can be achieved outside a trial setting, thrombolysis for acute stroke has become routine clinical practice in many centres. However, the call for further controlled evidence of the risk and benefits of acute thrombolysis is timely and justified as many uncertainties remain. ${ }^{34}$ One of these is the question whether patients over 80 years of age receive the same benefit from thrombolysis as younger patients. Although a descriptive study such as ours does not forestall the need for a controlled comparison study, its outcome may strengthen the controversy on the issue of age in acute thrombolysis, as in fact our data do. Our series' baseline characteristics as well as outcome results are similar to those of the NINDS trial and other patient series. ${ }^{15-10}$ Slight differences between the results of the various phase IV studies may be due to the heterogeneity of included patients in terms of age and initial NIHSS score. Although our SICH rate was similar to those in other phase IV studies and the NINDS study, we observed a higher mortality rate $(22 \% v 12-17 \%)$. This may relate to the high proportion of patients over 80 years of age in our study, as Kammersgaard et al demonstrated that besides stroke severity and pre-existing disability, old age is a strong and independent predictor of stroke prognosis. ${ }^{15}$ We found a significantly higher frequency of poor outcome in this group compared to patients $<80$ years of age, which could not be attributed to differences in those baseline characteristics that are associated with worse outcome such as pre-treatment blood pressure, NIHSS score, or time to treatment. Information on the outcome of rt-PA treatment in patients over 80 years of age is scarce. ${ }^{11}{ }^{12}$ Tanne et al found that favourable outcome (defined as an mRs score of 0 or 1 ) in their patients over 80 years of age was similar to that of patients under 80 years of age in the NINDS study. ${ }^{11}$ The difference with our data may be due to the selection of less severely ill elderly patients in the study by Tanne et al, as their elderly patients had slightly lower NIHSS scores at the start of treatment and a smaller proportion of their patients over 80 years of age had an NIHSS score $>20$. Our results are similar to those of Simon et al who in their case series treated the same percentage $(24 \%)$ of patients over 80 as we did. ${ }^{12}$ They found $32 \%$ mortality at 3 months, $20 \%$ favourable outcome, and 37\% good outcome. However, Simon et al did not compare outcome between the very old and remaining patients, and it therefore remains unclear to what extent the elderly fared worse than younger patients. Five of our nine patients with SICH were over 80. Although numbers are small, this finding suggests that more advanced age increases the risk of SICH $(11.1 \% \vee 2.9 \%)$. This was also found by Simon et al, but not by others. ${ }^{11}{ }^{12}$ As SICH occurred in regions other than the infarcted area in three of the five elderly patients compared to none in the patients $<80$ years of age, one might speculate that this complication is possibly due to degenerative vessel wall pathology such as amyloid angiopathy. Some argue that intravenous thrombolysis should be administered to the very old based on an individualised risk/benefit analysis. ${ }^{11}$ However, our findings underline the plea for more data on pre-specified groups from randomised controlled trials (RCTs) such as the Third International Stroke Trial. ${ }^{2}{ }^{4}$ Combining the results on functional independence and SICH in patients over 80 years of age, it is questionable whether the results achieved in RCTs in mainly younger patients can be extrapolated to this group. 
In conclusion, our study on thrombolytic therapy for acute ischemic stroke shows results similar to those achieved in the NINDS trial and phase IV studies. The results of our study underline the uncertainty regarding the benefit of rt-PA in patients over 80 years of age and raises the question whether the use of rt-PA is justified in patients over 80 years of age.

\section{Authors' affiliations}

R J van Oostenbrugge, R M M Hupperts, J Lodder, Department of Neurology, University Hospital Maastricht, Maastricht, The Netherlands

Competing interests: none declared

Correspondence to: Robert van Oostenbrugge, Department of Neurology, University Hospital Maastricht, PO Box 5800, 6202 AZ

Maastricht, The Netherlands; rvoo@sneu.azm.nl

Received 26 April 2005

Revised version received 22 August 2005

Accepted for publication 11 September 2005

\section{REFERENCES}

1 The NINDS rt-PA Stroke Study Group. Tissue plasminogen activator for acute ischaemic stroke. N Engl J Med 1995;333:1581-7.

2 Wardlaw JM, Del Zoppo G, Yamaguchi T, et al. Thrombolysis for acute ischaemic stroke. Cochrane Database Syst Rev 2003;(3):CD 000213

3 Warlow CP, Wardlaw JM. Therapeutic thrombolysis for acute ischemic stroke. BMJ 2003;326:233-4.
4 Lindley RI, Wardlaw JM, Sandercock PAG. Alteplase and ischaemic stroke: have new reviews of old data helped? Lancet Neurol 2005;4:254-7.

5 Chiu D, Krieger D, Villar-Cordova C, et al. Intravenous tissue plasminogen activator for acute ischemic stroke: feasibility, safety, and efficacy in the first year of clinical practice. Stroke 1998;29:18-22.

6 Grond M, Stenzel C, Schmülling S, et al. Early intravenous thrombolysis for acute ischemic stroke in a community-based approach. Stroke 1998;29:1544-9.

7 Kristine M, Chapman MD, Andrew R, et al. Intravenous tissue plasminogen activator for acute ischemic stroke. A Canadian hospital's experience. Stroke 2000;31:2920-4

8 Albers GW, Bates VE, Clark WM, et al. Intravenous tissue-type plasminogen activator for treatment of acute stroke. The Standard Treatment with Alteplase to Reverse Stroke (STARS) study. JAMA 2000;283:1 145-50.

9 Katzan IL, Furlan AJ, Lloyd LE, et al. Use of tissue-type plasminogen activator for acute ischemic stroke: the Cleveland area experience. JAMA 2000;283:1189-91.

10 Koennecke HC, Nohr R, Leistner S, et al. Intravenous tPA for ischemic stroke team performance over time, safety, and efficacy in a single-center, 2-year experience. Stroke $2001 ; 32: 1074-8$

11 Tanne D, Gorman MJ, Bates VE, et al. Intravenous tissue plasminogen activator for acute ischemic stroke in patients aged 80 years and older: the tPA stroke survey experience. Stroke 2000;31:370-5.

12 Simon JE, Sandler DL, Warwick Pexman JH, et al. Is intravenous recombinant tissue plasminogen activator (rt-PA) safe for use in patients over 80 years old with acute stroke? - The Calgary experience. Age Ageing 2004;33:143-9.

13 Hacke W, Kaste M, Fieschi C, et al. Intravenous thrombolysis with recombinant tissue plasminogen activator in acute hemispheric stroke. JAMA 1995; $274: 1017-25$.

14 Hyden P, Brott T, Tilley B, et al. Improved reliability of the NIH Stroke Scale using video training. Stroke 1994;25:2220-6.

15 Kammersgaard LP, Jørgensen HS, Reith J, et al. Short- and long-term prognosis for very old stroke patients. The Copenhagen Stroke Study. Age Ageing 2004;33:149-54. 